\title{
Kaempferol inhibits multiple pathways involved in the secretion of inflammatory mediators from LPS-induced rat intestinal microvascular endothelial cells
}

\author{
YIFEI BIAN, PING LIU, JIA ZHONG, YUSHENG HU, YINGSAI FAN, \\ SHEN ZHUANG and ZHONGJIE LIU \\ Division of Traditional Chinese Veterinary Medicine, College of Veterinary Medicine, \\ China Agricultural University, Beijing 100193, P.R. China
}

Received March 6, 2018; Accepted November 8, 2018

DOI: $10.3892 / \mathrm{mmr} .2018 .9777$

\begin{abstract}
Inflammatory bowel disease (IBD) is a chronic, idiopathic inflammatory disease of the small and/or large intestine. Endothelial expression of inflammatory mediators, including cytokines and adhesion molecules, serves a critical role in the initiation and progression of IBD. The dietary flavonoid, kaempferol, has been reported to inhibit expression of inflammatory mediators; however, the underlying mechanisms require further investigation. In the present study, a novel molecular mechanism of kaempferol against IBD was identified. The potential anti-inflammatory effect of kaempferol in a cellular model of intestinal inflammation was assessed using lipopolysaccharide (LPS)-induced rat intestinal microvascular endothelial cells (RIMVECs), and an underlying key molecular mechanism was identified. RIMVECs were pretreated with kaempferol of various concentrations $(12.5,25$ and $50 \mu \mathrm{M})$ followed by LPS $(10 \mu \mathrm{g} / \mathrm{ml})$ stimulation. ELISA was used to examine the protein levels of tumor necrosis factor- $\alpha$ (TNF- $\alpha$ ), interleukin-1 $\beta$ (IL-1 $\beta$ ), IL-6, intercellular adhesion molecule-1 (ICAM-1) and vascular cell adhesion molecule-1 (VCAM-1) in the supernatant. Protein expression levels of Toll-like receptor 4 (TLR4), nuclear factor- $\mathrm{kB}(\mathrm{NF}-\mathrm{\kappa B}) \mathrm{p} 65$, inhibitor of NF- $\mathrm{KB}$, mitogen-activated protein kinase $\mathrm{p} 38$ and signal transducer and activator of transcription (STAT) in cells were measured by western blotting. Kaempferol significantly reduced the overproduction of TNF- $\alpha$, IL-1 $\beta$, interleukin-6, ICAM-1 and VCAM-1 induced by LPS, indicating the negative regulation of kaempferol in
\end{abstract}

Correspondence to: Professor Zhongjie Liu, Division of Traditional Chinese Veterinary Medicine, College of Veterinary Medicine, China Agricultural University, 2 Yuan Ming Yuan West Road, Beijing 100193, P.R. China

E-mail: liuzhongjiecau@163.com

Key words: kaempferol, inflammatory bowel disease, inflammatory mediators, toll-like receptor 4 , nuclear factor- $\kappa \mathrm{B}$, mitogen-activated protein kinase, signal transducer and activator of transcription
TLR4, NF- $\kappa \mathrm{B}$ and STAT signaling underlying intestinal inflammation. The present results provide support for the potential use of kaempferol as an effective therapeutic agent for IBD treatment.

\section{Introduction}

Inflammatory bowel disease (IBD) primarily comprises two principal conditions, Crohn's disease and ulcerative colitis (UC), characterized by chronic gastrointestinal inflammation with alternating periods of relapse and remission (1). A variety of inflammatory mediators are involved in the pathogenesis of IBD, including tumor necrosis factor- $\alpha$ (TNF- $\alpha$ ), interleukin-1 $\beta$ (IL-1 $\beta$ ), IL-6 and intercellular adhesion molecule-1 (ICAM-1) (2). Excessive inflammatory mediators may lead to edema, ulceration and carcinogenesis of colon tissue $(2,3)$. Therefore, effective regulation of the secretion of inflammatory factors is essential for IBD treatment.

The etiology of IBD is not yet completely understood; it is believed that a complex interaction among genetic, immunological, metabolic, vascular, microbial and social factors leads to dysregulated and persistent inflammation (4). The current therapies for IBD rely highly on the use of immune suppressive drugs, including 5-aminosalicylic acid and corticosteroids (5). However, a number of patients either do not respond to these agents or demonstrate significant adverse effects (5). There is an urgent need to develop novel and effective anti-inflammatory substances with minimal side effects. Dietary flavonoids have been demonstrated to effectively and mildly regulate expression of inflammatory cytokines, alleviate the necrosis of colon tissue and relieve clinical symptoms in patients with $\operatorname{IBD}(6,7)$.

Kaempferol (3,5,7-trihydroxy-2-(4-hydroxyphenyl)4H-1-benzopyran-4-one), a flavonoid widely distributed in fruits, vegetables and plant-based foods, has been reported to possess anti-inflammatory, anti-diabetic, anti-hypertensive, anti-depressant and anti-ulcerative properties by acting on various cellular pathways (8-10). A previous study demonstrated that kaempferol had the most effective anti-inflammatory activities among eight polyphenols in a lipopolysaccharide (LPS)-induced Raw 264.7 cell model (11). In vivo studies additionally suggested that 
kaempferol exerts a distinct anti-inflammatory effect on dextran sulfate sodium-induced UC in mice (12). However, to the best of our knowledge, there are no studies at present that have focused on the role keampferol serves in LPS-induced intestinal microvascular endothelial cells. Intestinal microvascular endothelial cells, the primary components of the intestinal capillaries, have been demonstrated to be one of the most important secretory and immune cells in the process of inflammation, which is closely associated with the occurrence and progression of IBD $(12,13)$.

In order to further investigate the beneficial effect of kaempferol and the possible mechanisms involved in the intestinal inflammation process, LPS-stimulated rat intestinal microvascular endothelial cells (RIMVECs) were used to establish a cell model of IBD. It was demonstrated that kaempferol may alleviate LPS-induced inflammatory mediators, including TNF- $\alpha$, IL-1 $\beta$, IL-6, ICAM-1 and vascular cell adhesion molecule-1 (VCAM-1), by suppressing the activation of toll-like receptor 4 (TLR4), signal transducer and activator of transcription (STAT) and nuclear factor $-\kappa \mathrm{B}(\mathrm{NF}-\kappa \mathrm{B})$.

\section{Materials and methods}

Reagents and antibodies. Kaempferol (purity $\geq 98 \%$ ) was purchased from the National Institutes for Food and Drug Control (Beijing, China). Kaempferol was dissolved in dimethyl sulfoxide (DMSO); the final concentration of DMSO was $<0.1 \%(\mathrm{v} / \mathrm{v})$ when kaempferol was added to the experimental cells. Cell culture reagents, namely Dulbecco's modified Eagle's medium (DMEM) and fetal bovine serum (FBS) were obtained from Gibco (Thermo Fisher Scientific, Inc., Waltham, MA, USA). Endothelial cell growth supplement (ECGS) was purchased from EMD Millipore (Billerica, MA, USA). LPS (Escherichia coli 055:B5) was provided by Sigma-Aldrich (Merck KGaA, Darmstadt, Germany). The Cell Counting Kit-8 (CCK-8) was purchased from Dojindo Molecular Technologies, Inc. (Kumamoto, Japan). Rat TNF- $\alpha$ (cat. no. DY510), IL-1 $\beta$ (cat. no. DY501), IL-6 (cat. no. DY506), ICAM-1 (cat. no. DY583) and VCAM-1 (cat. no. DY809) ELISA kits were obtained from R\&D Systems, Inc. (Minneapolis, MN, USA). Antibodies for TLR4 (cat. no. ab22048), phosphorylated (p)-inhibitor of $\kappa \mathrm{B}(\mathrm{I}-\kappa \mathrm{B})$ (cat. no. ab133462) and p-NF- $\kappa \mathrm{B}$ p65 (cat. no. ab28856) were purchased from Abcam (Cambridge, UK). Antibodies for p-p38 (cat. no. 4511) mitogen-activated protein kinase (MAPK) and p-STAT (cat. no. 9145) were obtained from Cell Signaling Technology, Inc. (Danvers, MA, USA). The antibody against $\beta$-actin (cat. no. AC006) was purchased from ABclonal Biotech Co., Ltd. (Wuhan, China).

Cell culture and treatment. RIMVECs were isolated and cultured, as described previously $(14,15)$. A total of six neonatal rats at 1-day-old (gender undetermined; weight, 5-8 g) were purchased from the Academy of the Military Medical Sciences (Beijing, China). The present study was approved by the China Agriculture University Institutional Animal Care and Use Committee (approval no. CAU20160031201). RIMVECs were maintained with DMEM containing $15 \%$ (v/v) FBS, $0.5 \%(\mathrm{w} / \mathrm{v})$ ECGS, and $1 \%(\mathrm{v} / \mathrm{v})$ penicillin-streptomycin mixed solution. All cells were incubated at $37^{\circ} \mathrm{C}$ in a humidified incubator with $5 \% \mathrm{CO}_{2}$. Cells were starved in serum-free medium for $12 \mathrm{~h}$ prior to each experiment.
Cell viability assay. Cell viability was measured with a CCK-8 assay. RIMVECs were seeded at a density of $1 \times 10^{4}$ cells/well in 96-well plates for $24 \mathrm{~h}$. Subsequently, the cells were treated with $100 \mu \mathrm{l}$ of kaempferol at different concentrations $(200,10$ $0,50,25,12.5$ and $6.25 \mu \mathrm{M}$ ) for $12 \mathrm{~h}$. Following treatment, the medium was removed, and cells were cultured in $100 \mu \mathrm{l}$ fresh DMEM containing $10 \% \mathrm{CCK}-8$ solution at $37^{\circ} \mathrm{C}$ for $2 \mathrm{~h}$. Cell viability was determined by measuring the absorbance with a microplate reader (Bio-Rad Laboratories, Inc., Hercules, CA, USA) at $450 \mathrm{~nm}$.

Measurement of cytokines and adhesion protein. TNF- $\alpha$, IL-1 $\beta$, IL-6, ICAM-1, and VCAM-1 protein expression levels in culture supernatant were measured by ELISA, according to the manufacturer's protocol. RIMVECs were seeded in 12-well plates $\left(1 \times 10^{5}\right.$ cells/well). At $90 \%$ confluency, the cells were washed with PBS prior to the addition of medium with different concentrations of kaempferol (50, 25 and $12.5 \mu \mathrm{M})$. After $3 \mathrm{~h}$, cells were washed once with PBS and subsequently stimulated with $10 \mu \mathrm{g} / \mathrm{ml}$ LPS ( $1 \mathrm{ml} /$ well) for $6 \mathrm{~h}$ (TNF- $\alpha$, IL- $1 \beta$ and IL-6) or $12 \mathrm{~h}$ (ICAM-1 and VCAM-1) prior to the collection of the supernatant and measurement of inflammatory factors.

Western blot analysis. At the end of the incubation period, cells were lysed in radioimmunoprecipitation lysis buffer (2\% SDS; $10 \%$ glycerol; 62.5 mM Tris-HCl buffer; $\mathrm{pH} 6.8$ ) on ice. Protein concentrations were determined using a bicinchoninic acid protein assay kit (Beyotime Institute of Biotechnology, Haimen, China). Samples with equal quantities of total protein $(20 \mu \mathrm{g})$ were loaded and separated by $10 \%$ SDS-PAGE and transferred to nitrocellulose membranes (Pierce; Thermo Fisher Scientific, Inc.). The membranes were blocked in 5\% bovine serum albumin (Gibco; Thermo Fisher Scientific, Inc.) for $1 \mathrm{~h}$ at room temperature, and were immunoblotted with the specific primary antibodies against

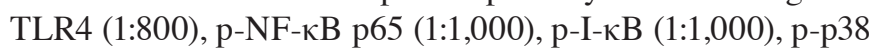
$(1: 800)$, p-STAT $(1: 800)$ and $\beta$-actin $(1: 2,000)$ overnight at $4^{\circ} \mathrm{C}$. Membranes were subsequently incubated with horseradish peroxidase-conjugated secondary antibody (1:10,000; Cell Signaling Technology, Inc.; cat. no. SC3901) for $1 \mathrm{~h}$ at room temperature. Subsequently, the blots were visualized with an enhanced chemiluminescence immunoblotting detection system (Beyotime Institute of Biotechnology) and quantified using ImageJ (v1.51; National Institutes of Health, Bethesda, MD, USA).

Statistical analysis. Data are expressed as mean \pm standard deviation, and analyzed by one-way analysis of variance followed by Student-Newman-Keuls test for multiple comparisons. All analyses were performed by GraphPad Prism 7 software (GraphPad Software Inc., La Jolla, CA, USA). P<0.05 was considered to indicate a statistically significant difference.

\section{Results}

Viability of RIMVECs treated with kaempferol. The chemical structure of kaempferol is presented in Fig. 1A. The cytotoxicity of kaempferol was assessed using the CCK- 8 assay. As demonstrated in Fig. 1B, a high concentration of kaempferol $(200 \mu \mathrm{M})$ significantly decreased cell viability $(\mathrm{P}<0.01)$; whereas, 
<smiles>O=c1c(O)c(-c2ccc(O)cc2)oc2cc(O)cc(O)c12</smiles>

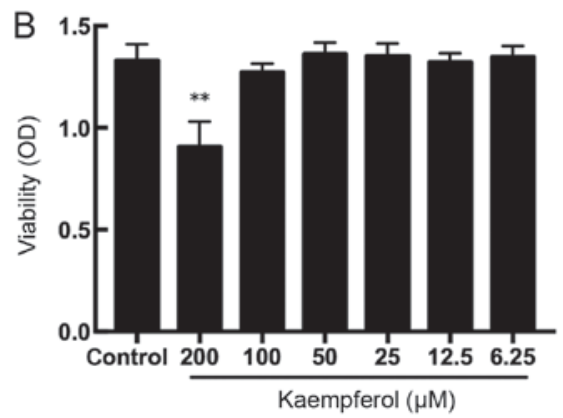

Figure 1. Effects of kaempferol on cell viability of rat intestinal microvascular endothelial cells. (A) Chemical structure of kaempferol. (B) Cells were incubated with different concentrations of kaempferol $(200,100,50,25$, 12.5 and $6.25 \mu \mathrm{M}$ ) for $12 \mathrm{~h}$. Cell viability was determined by a Cell Counting Kit- 8 assay. Data are presented as the mean \pm standard deviation. $\mathrm{n}=6$. ${ }^{* *} \mathrm{P}<0.01$ vs. control cells. OD, optical density.

treatment with concentrations between 6.25 and $100 \mu \mathrm{M}$ kaempferol exhibited no effect on cell viability. These results suggest that kaempferol is non-cytotoxic to RIMVECs within the concentrations of 3.125 and $100 \mu \mathrm{M}$. According to the results, concentrations of $12.5,25$ and $50 \mu \mathrm{M}$ kaempferol were selected for subsequent experimentation.

Kaempferol decreases TNF- $\alpha, I L-1 \beta$ and IL- 6 upregulation induced by LPS. Pretreatment for $3 \mathrm{~h}$ with kaempferol at different concentrations $(12.5,25$ and $50 \mu \mathrm{M})$ was followed by treatment with LPS $(10 \mu \mathrm{g} / \mathrm{ml})$ stimulation for $6 \mathrm{~h}$. As presented in Fig. 2, LPS stimulation significantly increased the secretion of inflammatory mediators above basal expression levels (Fig. 2A, TNF- $\alpha$, 2.61-fold; Fig. 2B, IL-1 $\beta, 2.36$-fold; Fig. 2C, IL-6, 4.25-fold; P<0.01). Pretreatment with kaempferol at all concentrations resulted in significant decreases in the concentrations of TNF- $\alpha$, IL-1 $\beta$ and IL- 6 compared with the LPS-model group $(\mathrm{P}<0.01)$.

Kaempferol partially suppresses LPS-induced ICAM-I and VCAM-1 overproduction. As presented in Fig. 3, LPS stimulation significantly increased the secretion of inflammatory mediators above the basal expression levels (Fig. 3A, ICAM-1, 2.04-fold; Fig. 3B, VCAM-1, 3.67-fold; P<0.01). Although no significant reduction in ICAM-1 and VCAM-1 secretion was observed in the $12.5 \mu \mathrm{M}$ kaempferol group, significant decreases in ICAM-1 and VCAM-1 concentration were observed in the 50 and $25 \mu \mathrm{M}$ kaempferol groups compared with the LPS-treated group $(\mathrm{P}<0.05)$.

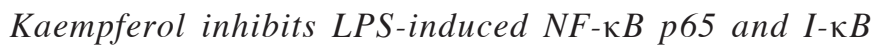
phosphorylation. The NF- $\mathrm{KB}$ pathway serves a critical role in the secretion of cytokines (10). The anti-inflammatory effect of kaempferol may be associated with the prevention
A
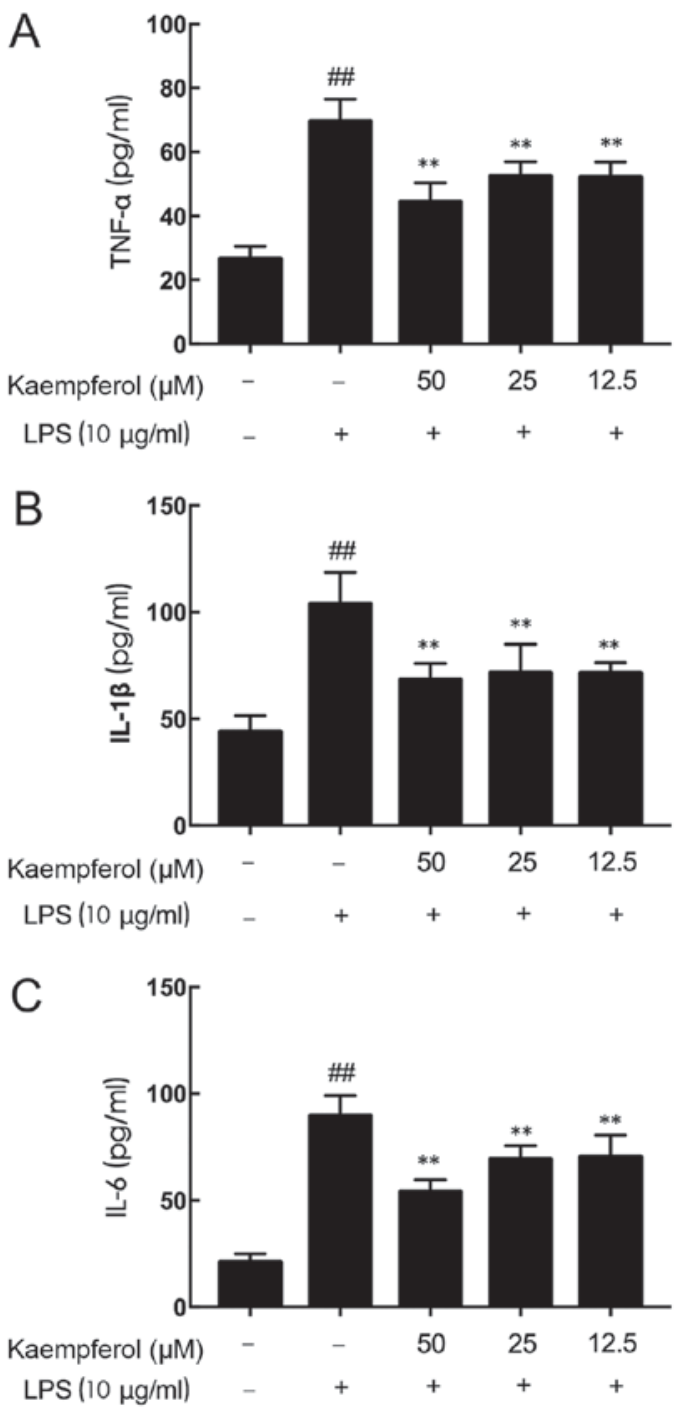

Figure 2. Kaempferol inhibits cytokine production induced by LPS in rat intestinal microvascular endothelial cells. Cells were treated with three different concentrations of kaempferol $(50,25$ and $12.5 \mu \mathrm{M})$ for $3 \mathrm{~h}$ and subsequently stimulated with LPS (10 $\mu \mathrm{g} / \mathrm{ml})$. After $6 \mathrm{~h}$, (A) TNF- $\alpha$, (B) IL-1 $\beta$ and (C) IL-6 protein secretion in the culture supernatant was quantified using an ELISA kit. Data are presented as the mean \pm standard deviation. $n=4$. ${ }^{\# \#} \mathrm{P}<0.01$ vs. control cells; ${ }^{* *} \mathrm{P}<0.01$ vs. cells stimulated with LPS. LPS, lipopolysaccharide; TNF- $\alpha$, tumor necrosis factor- $\alpha$; IL, interleukin.

of NF- $\mathrm{KB}$ activation. As presented in Fig. 4, there was a significant increase in the phosphorylation of the $\mathrm{p} 65$ subunit (p-NF- $\kappa \mathrm{B}$ p65/NF- $\kappa \mathrm{B}$ p65 ratio) and $\mathrm{I}-\kappa \mathrm{B}(\mathrm{p}-\mathrm{I}-\kappa \mathrm{B} / \mathrm{I}-\kappa \mathrm{B})$ in the model group compared with the control group $(\mathrm{P}<0.01)$. However, pretreatment with three different concentrations of kaempferol significantly decreased the LPS-induced increased $\mathrm{p}-\mathrm{NF}-\kappa \mathrm{B} \mathrm{p} 65 / \beta$-actin ratio $(\mathrm{P}<0.01)$. As for $\mathrm{I}-\kappa \mathrm{B}$, although 12.5 and $25 \mu \mathrm{M}$ kaempferol was not able to decrease the phosphorylation of I- $\kappa \mathrm{B}$ induced by LPS, treatment with $50 \mu \mathrm{M}$ kaempferol significantly decreased the $\mathrm{p}-\mathrm{I}-\kappa \mathrm{B}$ level $(\mathrm{P}<0.01)$.

Kaempferol inhibits LPS-induced TLR4 overexpression. Activation of the TLR4 signaling pathway may directly lead to the activation of NF- $\mathrm{KB}$ to regulate the production of cytokines $(9,10)$. The present results demonstrated that LPS significantly upregulated TLR4 expression (Fig. 5; P<0.01). Pretreatment with different concentrations of kaempferol 
A

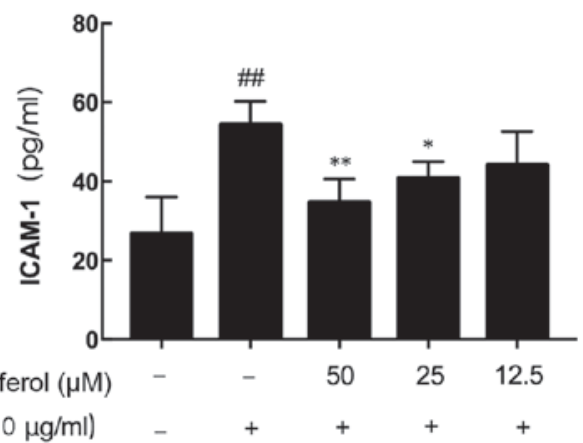

B

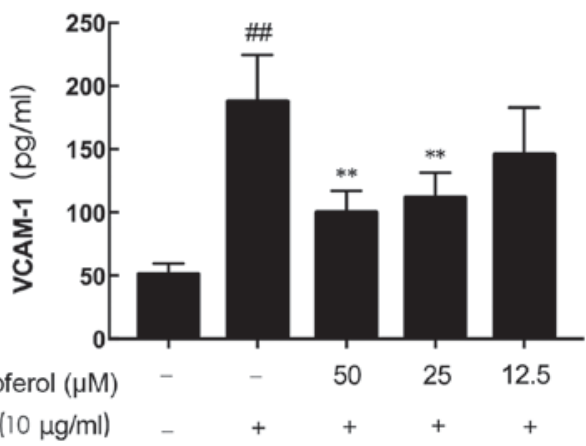

Figure 3. Kaempferol inhibits the production of adhesion protein induced by LPS in RIMVECs. RIMVECs were treated with three different concentrations of kaempferol $(50,25$ and $12.5 \mu \mathrm{M})$ for $3 \mathrm{~h}$ and subsequently stimulated with LPS $(10 \mu \mathrm{g} / \mathrm{ml})$. After $12 \mathrm{~h}$, (A) ICAM-1 and (B) VCAM-1 expression level in the culture supernatant was quantified with an ELISA kit. Data from individual experiments are presented as the mean \pm standard deviation. $\mathrm{n}=4$. ${ }^{\# \#} \mathrm{P}<0.01$ vs. control cells; ${ }^{*} \mathrm{P}<0.05,{ }^{* *} \mathrm{P}<0.01$ vs. cells stimulated with LPS. RIMVECs, rat intestinal microvascular endothelial cells; ICAM-1, intercellular adhesion molecule 1; LPS, lipopolysaccharide; VCAM-1, vascular cell adhesion molecule 1 .

significantly inhibited the LPS-induced overexpression of TLR4 (Fig. 5; P<0.01).

Kaempferol does not affect LPS-induced p38 MAPK phosphorylation. The p38 MAPK signaling pathway additionally serves an important role in inflammatory response. In response to LPS, the level of p-p38 was significantly upregulated in the model group compared with the control group (Fig. 6; $\mathrm{P}<0.01$ ). Compared with the model group, kaempferol at $50 \mu \mathrm{M}$ did not affect the expression level of p-p38.

Kaempferol inhibits LPS-induced STAT phosphorylation. The STAT pathway is another important inflammatory signaling pathway. As demonstrated in Fig. 7, cells subjected to LPS exhibited significantly increased STAT phosphorylation compared with the control group $(\mathrm{P}<0.01)$. By contrast, significant downregulation STAT phosphorylation was observed in the $50 \mu \mathrm{M}$ kaempferol treatment group compared with the model group $(\mathrm{P}<0.01)$.

\section{Discussion}

IBD is a chronic inflammatory disease of intestinal mucosa and submucosa, characterized by disruption of the intestinal epithelial barrier, increased production of inflammatory mediators and excessive tissue injury (16). Intestinal microvascular endothelial cells, the primary components of intestinal

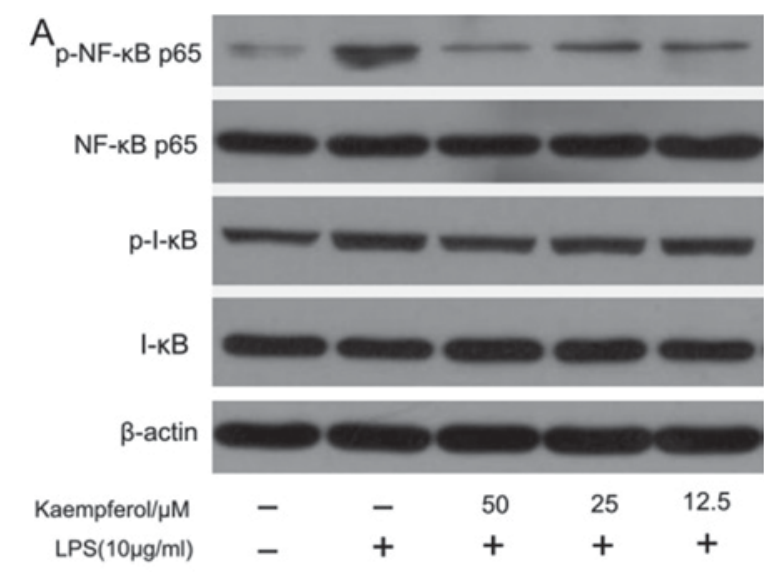

B
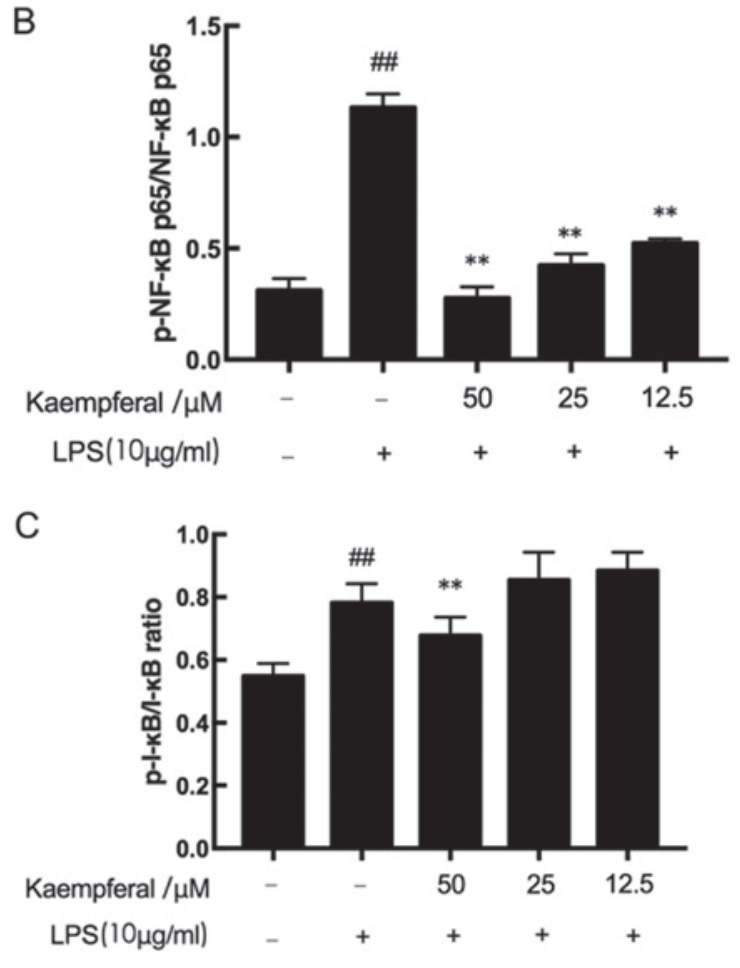

Figure 4. Kaempferol inhibits activation of NF- $\mathrm{B}$ induced by LPS in rat intestinal microvascular endothelial cells. Cells were treated with various concentrations $(50,25$ and $12.5 \mu \mathrm{M})$ of kaempferol for $3 \mathrm{~h}$ followed by treat-

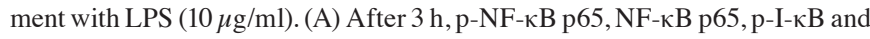
$\mathrm{I}-\kappa \mathrm{B}$ protein expression levels were analyzed by western blotting. (B) $\mathrm{p}-\mathrm{NF}-\kappa \mathrm{B}$ $\mathrm{p} 65 / \mathrm{NF}-\kappa \mathrm{B}$ and $(\mathrm{C}) \mathrm{p}-\mathrm{I}-\kappa \mathrm{B} / \mathrm{I}-\kappa \mathrm{B}$ ratios were determined by densitometry. Data are presented as the mean \pm standard deviation. $\mathrm{n}=3$. ${ }^{\# \#} \mathrm{P}<0.01$ vs. control cells; ${ }^{* *} \mathrm{P}<0.01$ vs. cells stimulated by LPS. p-, phosphorylated; NF- $\mathrm{B}$, nuclear factor- $\kappa \mathrm{B}$; I- $\kappa \mathrm{B}$, inhibitor of $\kappa \mathrm{B}$; LPS, lipopolysaccharide.

capillaries, have been demonstrated to be one of the most important secretory and immune cells in IBD (13). Intestinal microvascular endothelial cells produce and respond to inflammatory mediators $(17,18)$. As demonstrated in previous studies, in response to LPS stimulation, RIMVECs express the inflammatory cytokines, TNF- $\alpha$, IL- $1 \beta$ and IL- 6 , the chemokine IL-8, the adhesion molecule ICAM-1 and other inflammatory mediators, including nitric oxide and endothelin-1 $(14,19,20)$. Considering that LPS is a principal pro-inflammatory factor in the progression of IBD (21), LPS-stimulated RIMVECs were selected as a cellular model of intestinal inflammation.

Inflammatory mediators, including cytokines, adhesion proteins and chemokines, have an important role in 
A

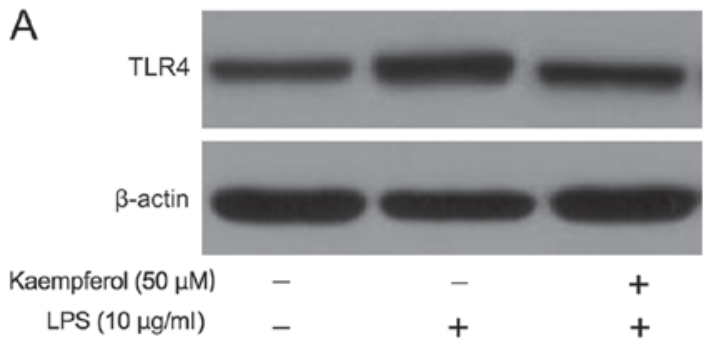

B

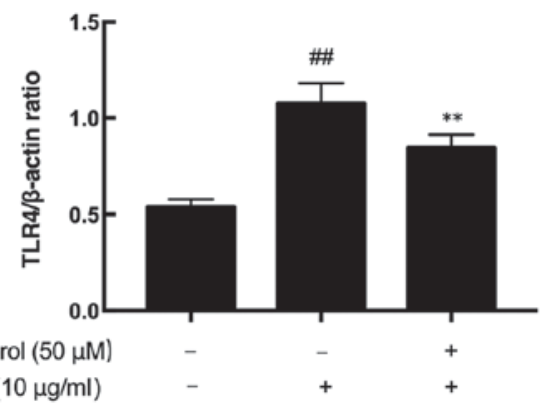

Figure 5. Kaempferol inhibits expression of TLR4 induced by LPS in RIMVECs. RIMVECs were pretreated with kaempferol $(50 \mu \mathrm{M})$ and subsequently stimulated with LPS $(10 \mu \mathrm{g} / \mathrm{ml})$ for $3 \mathrm{~h}$. TLR4 protein expression levels were determined by (A) western blotting and (B) densitometry analysis with $\beta$-actin as the loading control were performed. Data are presented as the mean \pm standard deviation. $n=3$. ${ }^{\# \#} \mathrm{P}<0.01$ vs. control cells; ${ }^{* *} \mathrm{P}<0.01$ vs. cells stimulated by LPS. RIMVECs, rat intestinal microvascular endothelial cells; TLR4, toll-like receptor 4; LPS, lipopolysaccharide.

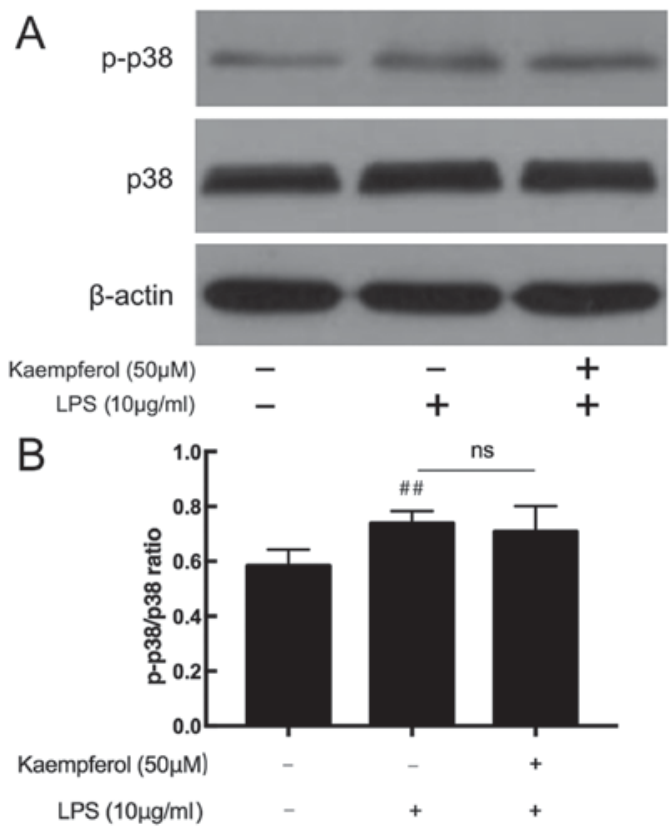

Figure 6. Kaempferol does not affect the phosphorylation of p38 mitogen-activated protein kinase induced by LPS in RIMVECs. RIMVECs were pretreated with kaempferol $(50 \mu \mathrm{M})$ and subsequently stimulated with LPS $(10 \mu \mathrm{g} / \mathrm{ml})$ for $3 \mathrm{~h}$. p-p38 expression was determined by (A) western blotting and (B) densitometry analysis with $\beta$-actin as the loading control. Data are presented as the mean \pm standard deviation. $\mathrm{n}=3$. ${ }^{\# \#} \mathrm{P}<0.01$ vs. contro cells. RIMVECs, rat intestinal microvascular endothelial cells; LPS, lipopolysaccharide; p-, phosphorylated.

the pathogenesis of IBD. TNF- $\alpha$ is the earliest and primary endogenous mediator in the inflammatory process. It has a pro-inflammatory effect through an increased production of

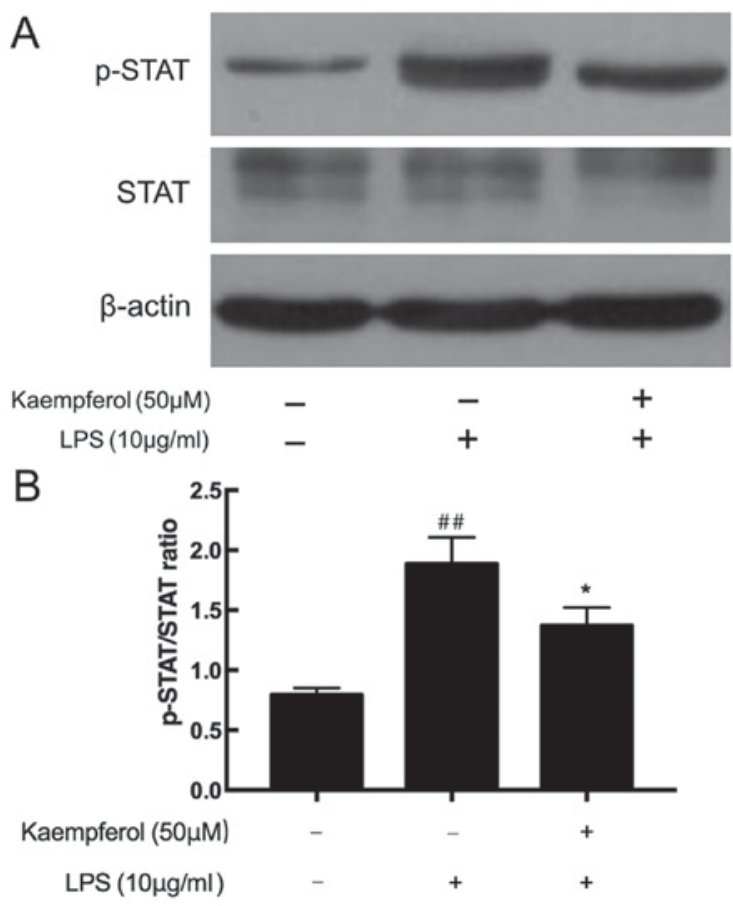

Figure 7. Kaempferol decreases the phosphorylation of STAT induced by LPS in RIMVECs. RIMVECs were pretreated with kaempferol $(50 \mu \mathrm{M})$ and subsequently stimulated with LPS $(10 \mu \mathrm{g} / \mathrm{ml})$ for $3 \mathrm{~h}$. p-STAT was measured by (A) western blotting and (B) densitometry analysis with $\beta$-actin as the loading control. Data are presented as the mean \pm standard deviation. $n=3$. ${ }^{\# \#} \mathrm{P}<0.01$ vs. control cells; ${ }^{*} \mathrm{P}<0.05$ vs. cells stimulated by LPS. RIMVECs, rat intestinal microvascular endothelial cells; $p$-, phosphorylated; STAT, signal transducer and activator of transcription; LPS, lipopolysaccharide.

IL-1 $\beta$, IL-6, adhesion molecules and pro-coagulant factors (17). Furthermore, TNF- $\alpha$ is an initiation factor of acute immune responses, cytotoxicity and apoptosis, but can also inhibit apoptosis $(2,22)$. In the present study, it was demonstrated that kaempferol was able to protect RIMVECs from LPS-induced overexpression of three inflammatory mediators, TNF- $\alpha$, IL-1 $\beta$ and IL-6. Therefore, the results of the present suggested that the inhibition of inflammatory cytokines may contribute to the protective effects of kaempferol in IBD.

In IBD, activation of microvascular endothelial cells and adhesion of circulating immune cells is required for the initiation and maintenance of inflammation (23). Pro-inflammatory cytokines, including TNF- $\alpha$ and IL-1 $\beta$, induce inflammatory responses in the vascular endothelium, which results in enhanced expression of cell adhesion molecules, including ICAM-1 and VCAM-1 (2). Overexpression of adhesion molecules in the intestinal endothelium may promote recruitment and adhesion of leukocytes, promoting the process of inflammatory response $(9,24)$. In the present study, the beneficial effect of kaempferol was demonstrated in the altered production of ICAM-1 and VCAM-1. The overexpression of ICAM-1 and VCAM-1 is involved in inflammatory processes; however, are additionally closely associated with intestinal carcinogenesis, secondary to IBD $(17,25)$. Therefore, the present results suggest that kaempferol may effectively reduce the expression of inflammatory mediators, against intestinal inflammation, and may reduce the risk of carcinogenesis in patients with IBD.

$\mathrm{NF}-\mathrm{\kappa B}$ has an essential role in regulating the expression of inflammatory cytokines and adhesion molecules (26). Due 
to the pivotal role of $\mathrm{NF}-\kappa \mathrm{B}$ in inflammation, the blockade of $\mathrm{NF}-\kappa \mathrm{B}$ activity is considered to be associated with inhibition of the inflammatory signaling cascade $(27,28)$. Inhibition of $\mathrm{NF}-\kappa \mathrm{B}$ activation is an effective strategy for preventing the progression of IBD in experimental animal models and preventing inflammatory cytokine production in patients with IBD (29). Under basal conditions, NF- $\kappa B$ is sequestered in the cytoplasm by a family of inhibitory proteins known as inhibitors of NF- $\mathrm{NB}$ (I- $\kappa \mathrm{Bs})$. Following stimulation with LPS, $\mathrm{NF}-\kappa \mathrm{B}$ is activated, triggering expression of a series of inflammatory cytokine (28). In the present study, LPS increased the phosphorylation of NF- $\kappa \mathrm{B}$ p 65 and $\mathrm{I}-\kappa \mathrm{B}$, which effectively indicates the activation level of $\mathrm{NF}-\kappa \mathrm{B}$. However, kaempferol significantly reduced the LPS-induced activation of NF- $\mathrm{NB}$, suggesting that the anti-inflammatory activities of kaempferol were due to the inhibitory effect on $\mathrm{NF}-\kappa \mathrm{B}$. The present study suggested a direct role of kaempferol in the prevention of LPS-stimulated NF- $\kappa \mathrm{B}$ activation in RIMVECs.

TLRs are pattern recognition receptors that 'sense' microbes and alert the immune system through activation of transcription factors (including $N F-\kappa B$ ) and the secretion of inflammatory mediators (9). TLR4 is the specific ligand of LPS, serving an important role in inflammatory disease, including IBD. Activation of TLR4 may lead to phosphorylation of MAPKs, I $\mathrm{B}$ kinases and NF- $\kappa \mathrm{B}$, eventually contributing to the expression of pro-inflammatory cytokines $(30,31)$. Compared with the significantly increased expression of TLR4 in LPS-treated RIMVECs, the administration of kaempferol significantly reduces the TLR4 expression in LPS-treated cells. This suggests that kaempferol may represent a novel strategy to limit the TLR4-mediated inflammatory process.

The MAPK signaling pathways, including extracellular signal-regulated kinase 1 and 2, c-jun $\mathrm{N}$-terminal kinase and p38, are closely associated with the expression of inflammatory mediators and oxidative damage (32). Previous studies demonstrated that MAPKs are highly activated and mediate pro-inflammatory cytokines, including TNF- $\alpha$, IL- $1 \beta$ and IL- 6 in the colon tissue of an IBD mice model and patients with IBD $(33,34)$. Kaempferol was demonstrated to suppress the expression of the LPS-induced MAPK pathway in the human monocytic cell line THP-1 (35), in addition to suppressing the production of cyclooxygenase-2 (COX-2), prostaglandin E2 and matrix metalloproteinases (MMPs) via MAPK in IL-1 $\beta$-induced rheumatoid arthritis synovial fibroblasts (36). Additionally, kaempferol treatment of the human synovial sarcoma cell line, SW982 cells, significantly inhibited IL-1 $\beta$-induced p38 MAPK phosphorylation, which were involved in the production of IL-6, IL-8, MMP and COX-2 (37). However, the role of kaempferol in IBD-associated cells has rarely been studied. In the present study, it was identified that kaempferol did not demonstrate any detectable influence on the phosphorylation of p38 in LPS-stimulated RIMVECs. The present results suggest that the anti-inflammatory effect of kaempferol is not dependent on the p38 MAPK pathway.

The STAT pathway is another crucial signaling cascade involved in IBD. It is well documented that the STAT pathway is not only associated with the inflammatory process in IBD; however, is additionally associated with further serious conditions, including colorectal cancer development $(38,39)$. Recent studies demonstrated that luteolin, a naturally occurring flavonoid, inhibited the Janus kinase (JAK)/STAT pathway in cytokine-induced HT-29 cells, a human epithelial cell line (39). Curcumin, a natural phenol, suppressed inflammation of TNBS-induced colitis in mice via STAT signaling (40). Although it was demonstrated that kaempferol attenuates inflammation by suppressing the STAT pathway in human airway epithelial cells (41), to the best of our knowledge, no study has focused on the effect of kaempferol on the JAK/STAT pathway in IBD-associated cells. The results of the present suggest that STAT may be associated with the suppressive effects of kaempferol against the production of inflammatory mediators in LPS-stimulated RIMVECs.

In conclusion, it was demonstrated that kaempferol significantly inhibits the LPS-induced expression of the inflammatory mediators TNF- $\alpha$, IL-1 $\beta$, IL-6, ICAM-1 and VCAM-1 by inhibiting TLR4, NF- $\kappa \mathrm{B}$ and STAT signaling, but not by activating p38 MAPK signaling in RIMVECs. The present results provide novel insight for the inflammatory effect of kaempferol in endothelial cells. It suggests that kaempferol may be an effective therapeutic agent for treatment of IBD, and that fruits and herbs rich in kaempferol may be incorporated into potential health care products for patients with IBD.

\section{Acknowledgements}

Not applicable.

\section{Funding}

The present study was funded by the National Natural Science Foundation of China (grant no. 31472228).

\section{Availability of data and materials}

All data generated or analyzed during this study are included in this published article.

\section{Authors' contributions}

YB designed and participated in all of the experiments, and was a major contributor in writing the manuscript. PL, JZ and YH were in charge of culturing the primary cells. YF and SZ performed the western blotting. ZL revised the manuscript, and was a major contributor in designing the experiments. All authors read and approved the final manuscript.

\section{Ethics approval and consent to participate}

The present study was approved by the China Agriculture University Institutional Animal Care and Use Committee (approval no. CAU20160031201).

\section{Patient consent for publication}

Not applicable.

\section{Competing interests}

The authors declare that they have no competing interests. 


\section{References}

1. Vezza T, Rodríguez-Nogales A, Algieri F, Utrilla MP, RodriguezCabezas ME and Galvez J: Flavonoids in inflammatory bowel disease: A review. Nutrients 8: 211, 2016.

2. Moldoveanu AC, Diculescu M and Braticevici CF: Cytokines in inflammatory bowel disease. Rom J Intern Med 53: 118-127, 2015.

3. Klampfer L: Cytokines, inflammation and colon cancer. Curr Cancer Drug Targets 11: 451-466, 2011.

4. Liu TC and Stappenbeck TS: Genetics and pathogenesis of inflammatory bowel disease. Annu Rev Pathol 11: 127-148, 2016.

5. de Boer NK, van Bodegraven AA, Jharap B, de Graaf P and Mulder CJ: Drug Insight: Pharmacology and toxicity of thiopurine therapy in patients with IBD. Nat Clin Pract Gastroenterol Hepatol 4: 686-694, 2007.

6. Dodda D, Chhajed R and Mishra J: Protective effect of quercetin against acetic acid induced inflammatory bowel disease (IBD) like symptoms in rats: Possible morphological and biochemical alterations. Pharmacol Rep 66: 169-173, 2014.

7. Park MY, Ji GE and Sung MK: Dietary kaempferol suppresses inflammation of dextran sulfate sodium-induced colitis in mice. Dig Dis Sci 57: 355-363, 2012.

8. Yao L, Yao J, Han C, Yang J, Chaudhry MT, Wang S, Liu H and Yin Y: Quercetin, Inflammation and Immunity. Nutrients 8: 167, 2016.

9. Bhaskar S, Sudhakaran PR and Helen A: Quercetin attenuates atherosclerotic inflammation and adhesion molecule expression by modulating TLR-NF- $\kappa \mathrm{B}$ signaling pathway. Cell Immunol 310: 131-140, 2016

10. Cho SY, Park SJ, Kwon MJ, Jeong TS, Bok SH, Choi WY, Jeong WI, Ryu SY, Do SH, Lee CS, et al: Quercetin suppresses proinflammatory cytokines production through MAP kinases andNF-kappaB pathway in lipopolysaccharide-stimulated macrophage. Mol Cell Biochem 243: 153-160, 2003.

11. Park MY, Kwon HJ and Sung MK: Evaluation of aloin and aloe-emodin as anti-inflammatory agents in aloe by using murine macrophages. Biosci Biotechnol Biochem 73: 828-832, 2009.

12. Binion DG, West GA, Ina K, Ziats NP, Emancipator SN and Fiocchi C: Enhanced leukocyte binding by intestinal microvascular endothelial cells in inflammatory bowel disease. Gastroenterology 112: 1895-1907, 1997.

13. Swerlick RA and Lawley TJ: Role of microvascular endothelia cells in inflammation. J Invest Dermatol 100 (Suppl): 111S-115S, 1993.

14. Duan H, Zhang Y, Xu J, Qiao J, Suo Z, Hu G and Mu X: Effect of anemonin on NO, ET-1 and ICAM-1 production in rat intestinal microvascular endothelial cells. J Ethnopharmacol 104: 362-366, 2006.

15. Suo Z, Mu X, Xu J, Wang Z, Wang X, Duan H, Hu G, Yang Z and Huang $\mathrm{H}$ : In vitro culture of rat intestinal mucous microvascular endothelial cells. Acta Anatomica Sinica 36: 214-217, 2005 (In Chinese).

16. Kasper JY, Hermanns MI, Cavelius C, Kraegeloh A, Jung T, Danzebrink R, Unger RE and Kirkpatrick CJ: The role of the intestinal microvasculature in inflammatory bowel disease: Studies with a modified Caco-2 model including endothelial cells resembling the intestinal barrier in vitro. Int J Nanomedicine 11: 6353-6364, 2016.

17. Francescone R, Hou V and Grivennikov SI: Cytokines, IBD, and colitis-associated cancer. Inflam Bowel Dis 21: 409-418, 2015.

18. Lu JT, Xu AT, Shen J and Ran ZH: Crosstalk between intestinal epithelial cell and adaptive immune cell in intestinal mucosal immunity. J Gastroenterol Hepatol 32: 975-980, 2017.

19. $\mathrm{Hu}$ YS, Lin RY, Bian YF, Fan K and Liu ZJ: Protective effect of kushenlu on lipopolysaccharide-induced small intestinal inflammation in rats. Int J Pharmacol 13: 473-480, 2017.

20. Liu J, Xue J, Zhu Z, Hu G and Ren X: Lactic acid inhibits NF-кB activation by lipopolysaccharide in rat intestinal mucosa microvascular endothelial cells. Agr Sci China 10: 954-959, 2011.

21. Xavier RJ and Podolsky DK: Unravelling the pathogenesis of inflammatory bowel disease. Nature 448: 427-434, 2007.

22. Xanthoulea S, Pasparakis M, Kousteni S, Brakebusch C, Wallach D, Bauer J, Lassmann H and Kollias G: Tumor Necrosis Factor (TNF) receptor shedding controls thresholds of innate immune activation that balance opposing TNF functions in infectious and inflammatory diseases. J Exp Med 200: 367-376, 2004.
23. Binion DG and Rafiee P: Is inflammatory bowel disease a vascular disease? Targeting angiogenesis improves chronic inflammation in inflammatory bowel disease. Gastroenterology 136: 400-403, 2009.

24. Medda R, Lyros O, Schmidt JL, Jovanovic N, Nie L, Link BJ, Otterson MF, Stoner GD, Shaker R and Rafiee P: Anti inflammatory and anti angiogenic effect of black raspberry extract on human esophageal and intestinal microvascular endothelial cells. Microvasc Res 97: 167-180, 2015.

25. Dhawan A, Friedrichs J, Bonin MV, Bejestani EP, Werner C, Wobus M, Chavakis T and Bornhäuser M: Breast cancer cells compete with hematopoietic stem and progenitor cells for intercellular adhesion molecule 1-mediated binding to the bone marrow microenvironment. Carcinogenesis 37: 759-767, 2016.

26. Chen X, Yang X, Liu T, Guan M, Feng X, Dong W, Chu X, Liu J, Tian X, Ci X, et al: Kaempferol regulates MAPKs and NF- $\kappa$ B signaling pathways to attenuate LPS-induced acute lung injury in mice. Int Immunopharmacol 14: 209-216, 2012.

27. Comalada M, Camuesco D, Sierra S, Ballester I, Xaus J, Gálvez J and Zarzuelo A: In vivo quercitrin anti-inflammatory effect involves release of quercetin, which inhibits inflammation through down-regulation of the NF-kappaB pathway. Eur J Immunol 35: 584-592, 2005.

28. Cui L, Feng L, Zhang ZH and Jia XB: The anti-inflammation effect of baicalin on experimental colitis through inhibiting TLR4/NF- $\kappa \mathrm{B}$ pathway activation. Int Immunopharmacol 23: 294-303, 2014.

29. Li Z, Zhang DK, Yi WQ, Ouyang Q, Chen YQ and Gan HT: NF-kappaB p65 antisense oligonucleotides may serve as a novel molecular approach for the treatment of patients with ulcerative colitis. Arch Med Res 39: 729-734, 2008.

30. Lucas K and Maes M: Role of the toll like receptor (TLR) radical cycle in chronic inflammation: Possible treatments targeting the TLR4 pathway. Mol Neurobiol 48: 190-204, 2013.

31. Akira S, Hoshino K and Kaisho T: The role of Toll-like receptors and MyD88 in innate immune responses. J Endotoxin Res 6 : 383-387, 2000.

32. Chen C, Chen YH and Lin WW: Involvement of p38 mitogen-activated protein kinase in lipopolysaccharide-induced iNOS and COX-2 expression in J774 macrophages. Immunology 97: 124-129, 1999.

33. Liu W, Liu Y, Wang Z, Yu T, Lu Q and Chen H: Suppression of MAPK and NF- $\mathrm{KB}$ pathways by schisandrin $\mathrm{B}$ contributes to attenuation of DSS-induced mice model of inflammatory bowel disease. Pharmazie 70: 598-603, 2015.

34. Amiot A and Peyrin-Biroulet L: Current, new and future biological agents on the horizon for the treatment of inflammatory bowel diseases. Ther Adv Gastroenter 8: 66-82, 2015.

35. Huang $\mathrm{CH}$, Jan RL, Kuo CH, Chu YT, Wang WL, Lee MS, Chen HN and Hung CH: Natural flavone kaempferol suppresses chemokines expression in human monocyte THP-1 cells through MAPK pathways. J Food Sci 75: H254-H259, 2010.

36. Yoon HY, Lee EG, Lee H, Cho IJ, Choi YJ, Sung MS, Yoo HG and Yoo WH: Kaempferol inhibits IL-1 $\beta$-induced proliferation of rheumatoid arthritis synovial fibroblasts and the production of COX-2, PGE2 and MMPs. Int J Mol Med 32: 971-977, 2013.

37. Lian JJ, Cheng BF, Gao YX, Xue H, Wang L, Wang M, Yang HJ and Feng ZW: Protective effect of kaempferol, a flavonoid widely present in varieties of edible plants, on IL-1 $\beta$-induced inflammatory response via inhibiting MAPK, Akt, and NF- $\mathrm{BB}$ signalling in SW982 cells. J Funct Foods 27: 214-222, 2016.

38. Slattery ML, Lundgreen A, Kadlubar SA, Bondurant KL and Wolff RK: JAK/STAT/SOCS-signaling pathway and colon and rectal cancer. Mol Carcinog 52: 155-166, 2013.

39. Nunes C, Almeida L, Barbosa RM and Laranjinha J: Luteolin suppresses the JAK/STAT pathway in a cellular model of intestinal inflammation. Food Funct 8: 387-396, 2017.

40. Zhao HM, Xu R, Huang XY, Cheng SM, Huang MF, Yue HY, Wang X, Zou Y, Lu AP and Liu DY: Curcumin suppressed activation of dendritic cells via JAK/STAT/SOCS signal in mice with experimental colitis. Front Pharmacol 7: 455, 2016.

41. Gong JH and Kang YH: Kaempferol inhibits chemokine expression and attenuates airway inflammation by suppressing STAT/JAK and NF-kB activity in human airway epithelial cells. FASEB J 25 (Suppl 1): lb1-1130.6, 2011. 